\title{
ENSURING ACCESS TO PAIN RELIEF AS HUMAN RIGHTS
}

\author{
Shapoval-Deinega K. ${ }^{1}$, Rokhanskiy A. ${ }^{2}$, Riga O. ${ }^{3}$, Penkov A. ${ }^{4}$ \\ IF RENAISSANCE ${ }^{1}$ \\ Kharkiv Regional Center of Palliative Medicine "Hospice"2 \\ Kharkiv National Medical University, Kharkiv, Ukraine ${ }^{3}$ \\ NGO "Eastern-Ukrainian Academy of Pediatrics"4
}

\begin{abstract}
The article presents the results of a selective study on the access to anesthesia. It has been determined that in most cases the goal of chronic pain management has not been achieved for a long time, the expected level of successful anesthesia has not been achieved in $80-90 \%$ of those in need, anesthesia is prescribed formally ("any prescription is a good prescription"), without taking into account clinical recommendations and clinical guidelines, that is doctors do not adhere to the principles of the WHO regarding the prescription of analgesics, approved by the Order of the Ministry of Health No. 311 as of 15 April 2012 "On the approval and implementation of medical and technological documents for standardization of palliative care in chronic pain syndrome". The authors believe that professional training of doctors requires changes regarding the quality of palliative care in accordance with WHO standards, wide implementation of modern scientific concepts of anesthesia in all areas of medical staff training.
\end{abstract}

Key words: palliative care, anesthesia, human rights.

"An acquaintance of mine, who is at the fourth stage of cancer, is not able to receive a prescription for anesthesia, morphine pellets, from the district doctor. According to international rules, a refusal to provide patients with anesthesia is equated with torture. How long will this last? Our lectures, trainings, and orders are all in vain. It is happening in Kharkiv region. Where to complain, where to write?"

(posted on Facebook, September 2017)

In 2010, representatives of the international organization Human Rights Watch (HRW) [1], who at that time conducted research on access to anesthesia and palliative care from the point of view of human rights in different countries of the world, drew the attention of the human rights community of Ukraine to a flagrant violation of human rights in the healthcare sector. The state

Corresponding Author:

Olena Riga, Doctor of Medical Sciences, Professor of Pediatrics No.1 and Neonatology Department, KhNMU, tel. +380662884409 e-mail: yeletskayaelena@gmail.com

ORCID https://orcid.org/0000-0003-0531-3914 of Ukraine tortures its sick citizens through numerous bureaucratic barriers and the lack of effective medicines in the pharmaceutical market that the whole world has recognized as the "gold standard" for the treatment of critically-ill patients with severe pain $[1,2]$.

Thus, during 2010, the first Ukrainian study on access to pain relief for patients with chronic pain was conducted. The findings of this study were published in two separate reports: the Human Rights Watch report "Uncontrolled pain. Obligations of Ukraine in the field of providing palliative care under the standards of evidencebased medicine" and a report by Ukrainian human rights organizations "We have the right to live without pain and suffering: a report by human rights organizations on the observance of the rights of palliative patients in Ukraine" [3, 4].

The 2010 studies allowed a number of important conclusions and recommendations that should be taken into account by the state of Ukraine in improving the state of human rights in the provision of palliative care. The researchers found that the rights of patients living at home, in the countryside and away from district centers and hospitals were largely not respected. 


\section{The studies showed violation} of the following fundamental human rights:

- The right not to be subjected to torture or cruel, inhuman or degrading treatment or punishment;

- The right of every person to the highest achievable level of physical and mental health [5].

In order to prevent the violation of the rights of people in need of palliative care and patients suffering from pain, in 2011, within the framework of the report of the Government of Ukraine, recommendations were made for improving the situation, most of which were fulfilled [6].

In 2016, seven human rights organizations, together with Human Rights Watch and with the support of the International Foundation "Renaissance", conducted a repeated study.

The purpose of the study was to determine the state of observance of the rights of patients in need of palliative care and access to anesthesia in Ukraine.

Materials and methods of the study. Separate observations, interviews and analysis of current legislation were carried out till September
2017. Respondents lived in large cities and rural areas or were treated at inpatient facilities that provide palliative care (hospitals, hospices). Interviews were conducted at patients' homes or in institutions with the assurance of the right to privacy, and with the informed consent of the respondents. Family physicians, therapists, and oncologists were interviewed for the purpose of examining the opinion of medical workers who directly provide medical care. A separate survey was conducted among government officials in the health care system of the city and regional levels. In total, the study involved assessment of 94 patient histories from 10 regions of Ukraine, as well as interviews with 50 health professionals and 11 public health officials.

Conflict of interest. Part of the study was funded by the International Foundation "Renaissance".

Results. The study in Ukraine was conducted on the basis of evidence-based medicine on the provision of palliative care and anesthesia (Table 1).

Table 1

"Uncontrolled pain" Obligations of Ukraine to provide palliative care according to the principles of evidence-based medicine 2011-2016

\begin{tabular}{|c|c|}
\hline $\begin{array}{c}\text { HRW recommendations, } 2011 . \\
\text { The Government } \\
\text { of Ukraine shall immediately: }\end{array}$ & The status of implementation of the recommendations, 2016 \\
\hline $\begin{array}{l}\text { Ensure the availability of oral } \\
\text { morphine } \\
\text { The government should actively } \\
\text { involve the company "Health of the } \\
\text { people" and other pharmaceutical } \\
\text { companies in the development and } \\
\text { manufacturing of oral morphine. The } \\
\text { public health system must ensure } \\
\text { that morphine is availableat all levels } \\
\text { of medical care }\end{array}$ & $\begin{array}{l}\text { endation was implemented in } \mathbf{2 0 1 3} \text {. } \\
\text { two national producers of oral morphine of immediate } \\
\text { n Ukraine. } \\
\text { ary } 1,2013 \text { INTERKHIM Additional Liability Company, } \\
\text { ty, became the first producer of morphine sulfate tablets } \\
\text { d } 10 \mathrm{mg} \text { ). } \\
\text { a Narody" Kharkiv Pharmaceutical Company Ldt, } \\
\text { ity became the second producer and received a license } \\
\text { ction of tablet Morphine-ZN (morphine hydro chloride, } \\
\text { mg and } 10 \mathrm{mg} \text { ) on December } 27,2013\end{array}$ \\
\hline $\begin{array}{l}\text { Cancel requirement that injectable } \\
\text { morphine and other strong pain } \\
\text { relief medications should be } \\
\text { administered to patients at home } \\
\text { by medical personnel. } \\
\text { In collaboration with doctors from WH } \\
\text { and other relevant experts to foresee } \\
\text { new standards for medication\$hat } \\
\text { patients take home to ensure a const } \\
\text { supply of pain relief medications. } \\
\text { For example, in areas where service } \\
\text { that delivers medicine to health care } \\
\text { facilities is functioning, patients shoul } \\
\text { be allowed to receive the medication } \\
\text { for } 7 \text { days to ensure continuous } \\
\text { availability of pain relief medications } \\
\text { while in rural areas where access to } \\
\text { health facilities that are licensed to } \\
\text { work with narcotic medications is }\end{array}$ & $\begin{array}{l}\text { ndation was partially implemented in 2013, fully } \\
\text { ted i } \mathbf{2 0 1 5 .} \\
3,2013 \text { the Cabinet of Ministers of Ukraine adopted } \\
\text { №333 "On approval of the procedure of acquisition, } \\
\text { tion, storage, dispensing, use and elimination of } \\
\text { ugs, psychotropic substances and precursors in health } \\
\text { ttion", which changed the procedure for prescription, } \\
\text { troduction of opioid analgesics. } \\
\text { eptember } 22,2015 \text { the provisions of the CMU } \\
\text { №333 contradicted with MoH Order №11 as of } \\
\text { "On approval of the Procedu re on circulation of } \\
\text { ugs, psychotropic substances and precursors in health } \\
\text { ttions in Ukraine", even though according to the CMU } \\
\text { №333, three months were given to harmonize the } \\
\text { r №11 was declared void by the MoH Order №494 as } \\
\text { t15 "On certain questions on acquisition, } \\
\text { tion, storage, dispensing, use and elimination of } \\
\text { ugs, psychotropic substances and precursors in health }\end{array}$ \\
\hline
\end{tabular}


MCU Resolution №333 changed the procedure of prescription and introduction of narcotic pain relief medications:

Paragraph 27. Patients being treated on an outpatient basis, including at home, shall be provided with narcotic drugs, psychotropic substances and precursors by health care institution or according to prescription by pharmaceuticals institutions in amounts that does not exceed ten-day needs and during palliative and hospice care - fifteen-day needs. Paragraph 28. To receive narcotic drugs, psychotropic substances and precursors for use at home patient himself or a person who provides care for him (family me mber, guardian or trustee) shall submit a request addressed to head of health care institution in the form set in Annex 3. Head of institution shall make a note of approval, after which the request is added to the outpatient's medical record.

CMU Resolution №333 as of May 13, 2013 does not require the introduction of injectable analgesics only by medical workers. Moreover, MoH Order №494 approved Information sheet for the patient or care-giver (family member, guardian or care-giver). The Information sheet includes information about the introduction of injections and rules for handling narcotic drugs.

On March 15, 2013 Ministry of Health approved the Order №203 "On amending MoH Order № 360 as of July 19, 2005”, which allowed patients not only to receive narcotic pain relief medications at the expense of the health care facilities, but to get them in pharmaceutical facilities upon prescription. Paragraph 1.18 "During the provision of palliative care to patients, including those who are entitled to a free-of-charge or subsidized provision of medications, it is allowed to prescribe the medications for fifteen-day need on one prescription form. When writing out such prescription, a doctor shall indicate "For chronically ill person".

Note:

MCU Resolution does not distinguish residents of urban and rural areas with regard to access to pain relief medications.

Pain relief medications may be prescribed to palliative patients in the amount for 10-15 day need regardless of the place of residence of the patient (CMU Resolution №333 as of May 13, 0213, MoH Order №41 as of January 21, 2013).

MoH Order №311 "On the approval and implementation of medical and technological documents on standardization of palliative care for patient with chronic pain syndrome" as of April 24, 2013 approved standards and principles of the WHO for the treatment of chronic pain, including pain scale, three step ladder pain management, principles of pain relief "by the clock" and others.

Instruction on the introduction of tablet morphine of Ukrainian production is based on the WHO recommendations: "Initial dose of the medication depend of the severity of pain and peculiarities of previous introduction of analgesics. Medication shall be administered every 4 hours. In case of increased severity of pain or tolerance to morphine, the dosage may be increased, and $5 \mathrm{mg}$ and $10 \mathrm{mg}$ dosage shall be used".

At the same time, the instruction for administration of morphine of Ukrainian production still does not meet the WHO recommendations; in particular regarding addiction. The instruction says: “... Morphine triggers strong euphoria. 
Repeated use of morphine lead to rapid development of psychic and physical dependence (after 2-14 days of treatment). Withdrawal symptoms may occur several hours after cessation of prolonged treatment and reach a maximum after 36-72 hours"- even though the treatment of chronic pain within the appropriate therapeutic dose cannot be accompanied by euphoria and repeat (multiple) usage cannot cause physical dependence (WHO recommendations).

Also maximum single and daily dose specified in the instruction do not meet WHO recommendations: "The maximum dose for subcutaneous administration for adults is $2 \mathrm{ml}$ (20 mg morphine) single dose and $5 \mathrm{ml}$ (50 mg morphine) daily" - although according to the WHO recommendations dose should be selected individually for each patient and his/her needs, single and daily doses may significantly exceed the instructions without impacting patient's health

\section{Change the licensing} requirements for health facilities in rural areas

Requirements for licenses to work with narcotic drug should be such so that all rural clinics could obtain such a license, including medical and obstetrical stations.

In particular, the Government shall consider whether there is a necessary requirement for a separate room for the storage of drugs in rural facilities, and whether it's an appropriate measure to protect against unauthorized use, and whether similar results may by achieved if safe is used in those facilities.

The Government should introduce a procedure where health care

facilities can get a license if they have simple sound and light signal system. rather than a system connected to the police station.

If the Government makes a decision to keep the current requirements that require expensive solutions, then the state should provide appropriate state funding for health care facilities.

\section{Distribute WHO guidelines on} pain relief among all health care facilities.

The Ministry of Health should encourage all physicians to

implement the recommendations of the Guidelines on pain assessment and treatment based on accurate pharmacological principles.

Provide in-service training on the use of protocols on pain relief for doctors throughout the health care system.

\section{Develop a system of palliative} care provision at home.

Review the structure of the staff of health care facilities in order to enable hospices and other institutions to provide palliative care to patients at home; provide funds to hospices to develop such services; to reform the current system of delivery of strong medications (nurses visiting patients at home) and transform it into a system of palliative care provision.

\section{Recommendation is partially implemented:}

Order of the Ministry of Internal Affairs of Ukraine № 216 "On approval of requirements for facilities and premises for activities with narcotic drugs, psychotropic substances, precursors and storage of seized drugs and such substances" as of 15.05.2009 in paragraph 2.1.4. sets the requirements for premises for storage of controlled medications: "...separate room in a capital building shall have safes or metal cabinets, secured to floor(walls); doors shall be well adjusted to the box, metal or wooden solid blocks with thickness not less than $40 \mathrm{~mm}$, and shall have at least two locks which cannot be closed independently; window aperture shall be equipped with metal bars on the inside or between the frames. Use of shutters which are not weaker than metal bars may be used".

Paragraph 3.1.4 of the MIA Order №216 states that: “...must be equipped with autonomous alarm system that protect the internal space and area, safes (metal cabinets) used for storage, with connection of alert signal to the remote district surveillance

or local sound and light signal.

\section{Partially implemented.}

On April 14, 2016, MoH approved Guidelines "Development of local protocols on palliative care for management of chronic pain syndrome"

Ministry of Health of Ukraine does not conduct inspections of health care facilities regarding their implementation of local protocols. Such monitoring, as well as training on skills for development of local protocols are carried out by NGOs.

\section{Partially implemented.}

Training for doctors about changes in legislation on handling controlled substances in health care facilities and usage of protocol on pain relief is conducted by NGO supported by donor organizations, including the International Renaissance Foundation.

\section{Legislation and regulations}

\section{Partially implemented.}

In 2012 Law of Ukraine "On amendment to the basic law of Ukraine on health care regarding improvement of health care provision" was adopted. The Law defined the palliative care as one of the types of medical care: "Article 35.4. Palliative care In the course of the last stages of incurable diseases patients are provided with palliative care, which includes measures aimed at alleviating physical and emotional suffering of patients and providing psychosocial and moral support to their families. Palliative care is provided free of charge upon referral of health institution where the patient was provided with secondary (specialized) or tertiary (highly specialized) medical care, which has an agreement on health services provision for the population. The procedure on palliative care and a list of medical indications for its provision are defined by central executive body in health care." 
Develop protocols on palliative care and pain management.

The Ministry of Health, medical universities, organizations providing palliative care and respective NGOs should develop protocols on palliative care and pain management based on information from international best practices. This clinical protocol should be widely distributed to all medical workers, and it will form the basis fo training of medical professionals in palliative care and pain management.
But these changes came into effect only on January 1, 2015.

Acting MoH Order №41 as of January 21, 2013 contains no specific staff regulations for hospice or on-site services.

Therefore, services based their activities on the Annex №50 to the $\mathrm{MoH}$ Order №33 as of February 23, 2000 until its cancellation on September 2, 2016.

Currently (as of December 2016) there are no regulations on the staffing, organizational structure of institutions providing palliative care. The cancellation of $\mathrm{MOH}$ Order №33 allows health care facilities to independently decide on the structure of the staff.

Approval MOH Order №41 preceded the entry into force of the Law of Ukraine.

In 2016 amendments to the $\mathrm{MOH}$ Order №41 are being developed by a working group of activists and practitioners. Among other important things, these changes shall define the peculiarities of pediatric palliative care.

The system of delivery of pain relief medications was changed by CMU Resolution №333 as of May 13, 2013. But in some areas there are still "narcotic treatment teams" which are carrying out the injections of morphine to patients. At the request of human rights organizations in particular in Kropyvnytskyi city, Kirovograd region, regarding the necessity of such type of service, the Department of Health during the "Forum on palliative care" held on September 23, 2016 reported that such service is necessary for the attendance of single patients or patients who do require such services.

Since 2014 Institute for Legal Research and Strategies NGO, together with the National Preventive Mechanisms under Ombudsman, investigates the situation of all health care facilities and social protection institutions, which could be considered as those that provide palliative care. Preliminary monitoring results indicate that $2 / 3$ of facilities designed to provide palliative care, do not meet the minimum standards of WHO and international organizations regarding palliative care Partially implemented.

Order of the Ministry of Health of Ukraine №311 " On the approval and implementation of medical and technological documents on standardization of palliative care for patient with chronic pain syndrome" as of April 24, 2012 " established standards and principles of WHO for the treatment of chronic pain syndrome.

In 2016 medical and technical documents on standardization of palliative medical care for adults with chronic pain syndrome are being reviewed by a working group of Ministry of Health of Ukraine.

In 2016 working group selected WHO protocol as a priority document to work on the development of medical and technical documentation for pharmacological treatment of chronic pain for children.

In 2016 working group is finalizing medical and technical documents on standardization of palliative care for patients with HIVIAIDS. The initial protocol was approved by the MoH Order №368 as of July 3, 2007.

According to the provisions of $\mathrm{MoH}$ Order №41 "On organization of palliative care" as of January 21, 2013 patients with HIVIAIDs cannot stay in general hospices or palliative care departments. The main reasons for refusal to take such patients is the inability to provide sanitary conditions for HIV-infected patients in these institutions. According to human rights advocates, this provision is discriminatory and shall be removed from the Order. Partially implemented.

Ensure the integration of palliative care into strategies for disease prevention.

The national programs on HIVIAIDS and cancer, as well as respective strategies for prevention of other diseases shall include a powerful palliative component have a list of steps to be taken to integrate palliative care into these strategies, and provide targeted and appropriate funding for the development of palliative care.
The issue of palliative care is included into program for prevention of cancer by 2016. But, unfortunately, there is no funding foreseen

http://zakon2.rada.gov.ua/laws/show/1794-17/page2 


\section{Licensing requirements.}

These requirements should be the less burdensome, while providing protection from possible misuse and theft. The Government should consider the possibility of using safes for storage of small amounts of opioid medications, which are likely to be stored in rural hospitals.
Medicines for use at home. In many countries in the world it is a standard practice to give patients morphine supply for use at home for a period from two weeks to one month.
- Promoting domestic production of tablet morphine,

- Establishing a system of state support for drug producers and pharmacies that have license for circulation of narcotic medications in order to expand their range and availability; - Providing health care facilities and pharmacy network with tablet forms of prolonged opioid analgesics;

- Creating the necessary conditions for the safe use of narcotic drugs in the "in patient facility at home";

- Prescribing narcotic medications to patients withronic pain of cancer and noncancer nature by doctor without further approval and revision by medical board;

- Including compulsory course on palliative care into undergraduate and postgraduateraining programs for doctors, paramedics, nurses, counselors and social workers. "

\section{Partially implemented.}

The government did not consider the use of safe, which can quite reliable protect small amounts of opioid medication in rural hospitals.

Licensing requirements were simplified and system of filling in documents for obtaining a license was improved under the CMU Resolution №282 "Some issues of licensing the cultivation of plants included into Table I of the List of narcotic drugs, psychotropic substances and precursors, approved by the Cabinet of Ministers of Ukraine, development, production, manufacture, storage, transportation, purchase, sale (delivery), import into Ukraine, export from Ukraine, use, destruction of narcotic drugs, psychotropic substances and precursors included in this list" as of April 6, 2016.

In particular, the list of required documents to obtain a license was simplified to 8 items. Also paragraph 28 of the Resolution states: "In case two health care facilities share the space for storage, narcotic drugs, psychotropic substances and precursors shall be stored in individual safes (cabinets). Sharing space is confirmed by the relevant agreements", which reduces the cost of preparing the facilities for the storage of controlled medications.

\section{Implemented.}

Pain relief medications may be prescribed to palliative patients for a period of 10-15 days regardless of the place of residence of the patient - CMU Resolution №333 of May 13, 2013; $\mathrm{MoH}$ Order №360 as of July 19, 2005.

Note:

Medical staff having all legal grounds to prescribe adequate pain relief medications, often do not ensure the sufficient amount of medications for palliative patients. This primarily happens due to limited finances to purchase pain relief medications, lack of understanding of managers of health care facilities of need to clearly identify the need and lay the funds for the purchase of pain relief medications, lack of regular mechanisms for calculating needs.

There have been cases recorded when managers of health care facilities, referring to the CMU Resolution №240 as of February 7,2014 "Issue of declaration of change of wholesale selling prices for medicines and medical products" emphasized that it is very hard to set procurement prices for the pain relief medications:

"1) Since August 1, 2014 changes in wholesale prices shall be declared excluding taxes and fees for:

medicines included in the list of medicines of domestic and foreign production, which can be purchased by health care facilities and institutions, that re fully or partially financed from state and local budgets approved by the CMU Resolution №1071 as of September 5, 1996 "Order of procurement of medications by health care facilities and institutions at the expense of the budget "(Article 480 of the Law of Ukraine №17, 1996), except narcotic and psychotropic drugs, precursors, drug substances (substances), medical gases and dosage forms produced in pharmacies from the substances and excipients permitted according to prescription and as requested by health care facilities."

\section{Recording procedures should be Implemented}

simplified to minimize waste of CMU Resolution

MoH Order №360 as of July 19, 2005.

$\mathrm{MoH}$ Order №494 as of August 7, 2015 


\begin{tabular}{|c|c|}
\hline $\begin{array}{l}\text { Number of signatures for a } \\
\text { prescription shall be reduced. } \\
\text { Doctors in most countries can make } \\
\text { their own decisions about } \\
\text { prescription of opioid analgesics. }\end{array}$ & $\begin{array}{l}\text { Implemented } \\
\text { CMU Resolution №333 as of May 13, } 2013 . \\
\text { MoH Order №360 as of July 19, } 2005 . \\
\text { MoH Order №494 as of August } 7,2015 . \\
\text { Decisions about prescription of opioid analgesics are taken by } \\
\text { the attending physician and recorded to the patient historylcard. } \\
\text { CMU Resolution №333 as of May 13, 2013: } \\
\text { "Paragraph 26. Prescription of narcotics drugs, psychotropic } \\
\text { substances and precursors to patients for more than ten days } \\
\text { shall be done by the attending doctor with obligatory reasoning } \\
\text { of further use of such drugs, which is recorded in the medical } \\
\text { record of the patient. Prescription sheet shall be stored in the } \\
\text { patient's medical record." } \\
\text { MOH Order №360 as of July 19, 2005: } \\
\text { "1.4. Prescriptions shall be stamped with square stamp of the } \\
\text { health care facilities and certified by signature and personal seal } \\
\text { of a doctor, and in the cases stipulated by this order (para. } 1.14 \\
\text { (appointment of narcotic (psychotropic) drugs on the prescription } \\
\text { form F-3)) additionally by a round seal of the entity, which } \\
\text { carries out activities related to medical practice. } \\
\text { 1.13. Prescription form F-3 shall be additionally signed by the } \\
\text { head of health care facility or deputy head on clinical work (and } \\
\text { in their absence - the signature of the head of the department, } \\
\text { who is responsible for the appointment of narcotic (psychotropic) } \\
\text { drugs) and certified by the seal of the entity, which carries out } \\
\text { activities related to medical practice. } \\
\text { 1.12. All specific instructions, notes of the medical worker } \\
\text { ("Chronically ill", "For special purpose") are additionally certified } \\
\text { by signature and seal of the doctor. } \\
\text { 1.18. If necessary (business trip, vacation etc.), patients, } \\
\text { including those who are entitled to free or subsidized provision } \\
\text { of medication, is allowed to receive prescription for medications } \\
\text { in amount for three-month need, taking into account the rules of } \\
\text { supply of medicines. } \\
\text { When providing palliative care to patient, including those who } \\
\text { are entitled to free or subsidized provision of medications, is } \\
\text { allowed to receive prescription for medications in amount for } \\
\text { fifteen-day need. When writing out prescription, an indication } \\
\text { "Chronically ill" shall be made". }\end{array}$ \\
\hline
\end{tabular}

\section{Conclusions:}

1. A sampling study showed that in most cases, the goal of treatment for chronic pain, namely the elimination of pain or its significant reduction for a long time, was not achieved.

2 . The expected level of successful anesthesia has not been achieved in $80-90 \%$ of those in need; conditionally successful anesthesia has been achieved in $5-14 \%$ of patients.

3. Anesthesia is prescribed formally ("any prescription is a good prescription"), without taking into account clinical recommendations and clinical guidelines, that is, physicians do not adhere to the principles of the WHO regarding the prescription of analgesics, approved by the Order of the Ministry of Health No.311 as of 25 April 2012 "On the approval and implementation of medical and technological documents for standardization of palliative care in chronic pain syndrome".
4. According to interview materials, the formal prescription of anesthetic regimens and the lack of doctors' desire to achieve success in pain management can only be explained by the reluctance of medical professionals to perform their professional duties - to treat chronic pain syndrome. Separate explanations from physicians concern the fears of causing drug dependence, or fears of provoking respiratory depression in patients, or ignorance of the orders of the Ministry of Health - all these excuses cover the Soviet tradition of medical education: not to prescribe opioids for pain relief in any case.

5. Professional training of doctors requires changes regarding the quality of palliative care in accordance with WHO standards, wide implementation of modern scientific concepts of anesthesia in all areas of medical staff training [8-18]. 


\section{References}

1. Human Rights Watch, 350 Fifth Avenue, 34th floor, New York, NY 10118-3299 USA, Tel: +1 212290 4700, Fax: +12127361300, hrwnyc@hrw.org

2. Human Rights Watch (2009). Please, do not make us suffer any more. Access to Pain Treatment as a Human Right. Ruth Fremson/The New York Times/Redux, ð. 45. Available at:

https://www.hrw.org/sites/default/files/reports/health0309ruwebwcover.pdf

3. Human Rights Watch (2011). Uncontrolled Pain. Ukraine's Obligation to Ensure. Evidence-Based Palliative Care. Scott Anger \& Bob Sacha/Open Society Foundations, ð. 94. Available at:

https://www.hrw.org/sites/default/files/reports/ukraine0511rusWebVersion.pdf

4. Rohanskij A., Kotenko A., Lazarevich Ju. i drugie (2012). My imeem pravo zhit' bez boli i stradanij otchet pravozashhitnyh organizacij o sobljudenii prav palliativnyh pacientov Ukrainy. [We have the right to live without pain and suffering the report of human rights organizations on the observance of the rights of palliative patients in Ukraine]. Kiev: Izdatel'skij dom "Kalita", p. 112.

5. Senjuti ${ }^{2}$.Ja. (2015). Prava ljudini v galuz ${ }^{3}$ ohoroni zdorov'ja 2007-2016. [Human rights in the health galusies 2007-2016]. 5-te vid., dop. - L'v³: Vidavnictvo LOBF "Medicina ${ }^{3}$ pravo", p. 989.

6. Theunissen, J.M., et al. (2007). Symptoms in the palliative phase of children with cancer. Pediatr Blood Cancer, 49(2), pð. 160-165.

7. Riga O.O., Marabyan R.V., Penkov A. Yu. et al (2015). Problems and development prospects of children's palliative care in Ukraine. Family Medicine, 6 (62), ðð. 138-140.

8. Joan MarstonrI GA, Riga O., Marston J, Penkov A. (2016) The first experience of mobile pediatric palliative team in Ukraine. Zaporoxhian Medical Journal, 6(99), ðð. 62-66.

9. Riga O., Gonchar M., Konovalova N., Marabyan R. (2016). Outcomes And Need Of Palliative Care For Children With Paralitics Syndrome". 6th Congress of the European Academy of Paediatric Societies, ð.409.

10. Penkov A., Riga O., Gonchar M., Marabyan R. et al (2016). "Access To Palliative Care For Children In Ukraine - Challenges And Views". 3rd Congress on Pediatrics Palliative Care), Abstract book, ð.112.

11. R³ga O.O., Gonchar' M.O. Marabjan R.V., Pen'kov A.Ju. i drugie (2016). Problemi ta perspektivi rozvitku ped ${ }^{3}$ atrichno $\dot{\dot{c}}$ pal ${ }^{3} a t i v n o \dot{d}$ dopomogi. [ Problems and prospects of pediatric palliative care

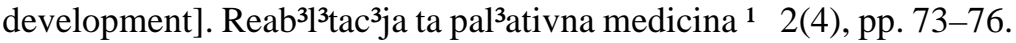

12. Rga O.O., Osichnjuk L.M., Marabjan R.V. (2016). Oc ${ }^{3} n k a$ bol'ovogo sindromu u d $d^{3}$ tej ${ }^{3} z$ nevrolog ${ }^{3} \mathrm{chnoju}$ patolog ${ }^{30} \mathrm{ju} \mathrm{H}^{3} \mathrm{rurg}^{3} \mathrm{ja}$ Donbasu. [Evaluation of pain syndrome in children with neurological pathology of the Donbass Surgery]. Tom 5, ${ }^{1}$ 3, pp. 59-64.

13. R'3a O.O., Marston Joan, Gonchar' M.O., Pen'kov A.Ju. (2016). Ped³atrichna pal3ativna dopomoga $\mathrm{v}$ praktic ${ }^{3}$ ditjachogo endokrinologa. [Pediatric palliative care in the practice of children's endocrinologist]. Mater ${ }^{3} a l i$ naukovo-praktichno ¿konferenc ${ }^{33} \mathrm{z} \mathrm{m}^{3}$ zhnarodnoju uchastju "Endokrinna patologija u v³kovomu aspekt ${ }^{3 "}$, ðð. 74-75.

14. Rga O.O. Marabjan R.V., Gavrish T., Pen'kov A. i drugie (2015). Chi ${ }^{\circ}$ lokal' ${ }^{3}$ protokoli pal3ativno $\dot{c}$ dopomogi dlja d $\mathrm{d}^{3} \mathrm{tej} v \mathrm{v}$ ustanovah. [ Are there any local palliative care protocols for children in institutions].

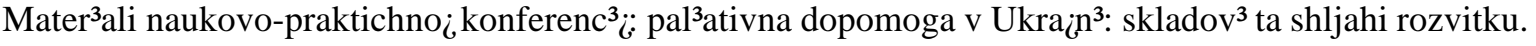

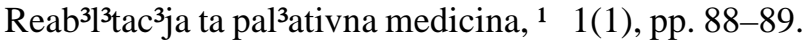

15. Gonchar' M.O., R³ga O.O., Pen'kov A.Ju. (2015). Principi nadannja pal3ativno ¿dopomogi dtjam: pershij dosv ${ }^{3} \mathrm{~d}$ vizznih pal ${ }^{3} a t i v n i h$ brigad $v$ Hark ${ }^{3} v s^{\prime} k_{i j}$ oblast ${ }^{3}$ Navchal'nij pos $^{3}$ bnik. [Principles of the provision of palliative care for children: the first experience of visiting palliative brigades in the Kharkiv region]. Vidavnictvo RAART-MAK, Hark³ v, p. 112.

16. R³a O.O., Koval'ova O.M., Korobka O.V., Gonchar' M.O. i drugie (2015). Palªtivna dopomoga u novonarodzhenih: mediko-etichn ${ }^{3}$ ta $\mathrm{f}^{3}$ nansovo-ekonom ${ }^{3} \mathrm{chn}^{3}$ aspekti. [Palliative care for newborns: medical and ethical and financial and economic aspects]. Ekonom ${ }^{3} \mathrm{ka}^{3}$ pravo ohoroni zdorov'ja, ${ }^{1}{ }^{1}$, pp. 31-35.

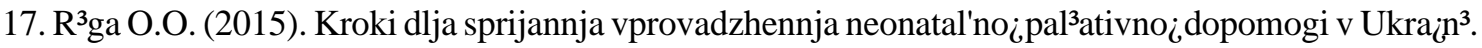
[Steps to Promote the Implementation of Neonatal Palliative Care in Ukraine]. Neonatolog3ja, h3rurg3ja ta perinatal'na medicina T V ${ }^{1} 2$ (16), pp. 5-10.

18. Rohans'kij A. O. (2016). Prava ljudini v galuz ${ }^{3}$ ohoroni zdorov'ja 2015-2016 (persha polovina): dopov ${ }^{3} \mathrm{~d}^{\prime}$ pravozahisnih organ ${ }^{3} \mathrm{zac}^{3} \mathrm{j}$. [Human rights in the field of healthcare 2015-2016 (first half): report of human rights organizations]. ${ }^{2} \mathrm{n}-\mathrm{t}$ prav. dosl ${ }^{3} \mathrm{dzh} .{ }^{3}$ strateg$^{3} \mathrm{j}$. Hark ${ }^{3} \mathrm{v}$ : Prava ljudini, p. 107. 